\title{
"O nosso amor a gente inventa": discursos e práticas amorosos homo e heterossexuais
}

\section{Resumo}

Meu objetivo é colocar em foco as diferentes percepções acerca do amor e de sua prática a partir dos dados levantados em minha tese de doutorado, em que investiguei a vivência amorosa de parcerias afetivo-sexuais pertencentes aos segmentos médios do universo homo e heterossexual. Para o grupo entrevistado, o amor apresenta dois sentidos principais: um deles, associado ao ideal do amor romântico, que resulta numa sua visão naturalizada e na ideia de incompletude; o outro, associado à noção de que o amor se constrói cotidianamente, tem como elementos mais importantes o companheirismo, o carinho e o respeito. Ambas as visões se sobrepõem, dando uma configuração muito particular à pratica amorosa.

Palavras-chave: Amor; amor romântico; homossexualidade e heterossexualidade.
Telma Amaral Gonçalves Doutora em Antropologia e professora da Universidade Federal do Pará - Brasil. telmaral@ufpa.br

\section{Para citar este artigo:}

AMARAL GONÇALVES, Telma. "O nosso amor a gente inventa": discursos e práticas amorosos homo e heterossexuais. Revista PerCursos. Florianópolis, v. 15, n.28, p. 337 - 353. jan./jun. 2014. 


\title{
"Our love we invent": homosexual and heterosexual loving discourses and practices
}

\begin{abstract}
My goal is to put focus on the different perceptions of love and its practice from the data collected in my doctoral thesis which investigated the loving experience of emotional-sexual partners belonging to middle segments of universes homo and heterosexual. For the group interviewed the love has two main directions, one of them associated with the ideal of romantic love which results in a naturalized view of it and the idea of incompleteness, and the other associated with the notion that love is built daily and has the most important elements companionship, affection and respect. Both views overlap giving a very particular to practice loving.
\end{abstract}

Keywords: Love; romantic love; homosexuality and heterosexuality. 
Em minha tese de doutoramento, Falando de amor: discursos sobre o amor $e$ práticas amorosas na contemporaneidade (AMARAL GONÇALVES, 2011), investiguei o amor enquanto discurso e prática entre parcerias afetivo-sexuais pertencentes aos segmentos médios do universo homo e heterossexual. A articulação entre estes dois campos me possibilitou identificar uma multiplicidade de arranjos domésticos e/ou afetivos, com ênfase entre os pares heterossexuais, num modelo aparentemente "tradicional" no que se refere à forma, pois os pares eram casados no civil e/ou no religioso, coabitavam, tinham filhos, viviam um relacionamento que variava de 3 a 52 anos de duração e comungavam o ideal de divisão equânime de despesas e responsabilidades.

Em contrapartida, o universo homossexual apresentou uma configuração específica e menos canônica em cada um dos casos. O tempo de relacionamento variava de 1 a 22 anos, com coabitação e ausência de filhos. Ainda que houvesse, de alguma forma, divisão de despesas e responsabilidades, em alguns casos, os pares não possuíam espaço independente - o que resultava na incorporação de um dos parceiros(as) ao núcleo familiar do outro -, o que dava ao relacionamento uma configuração muito particular, implicando uma percepção diferenciada do compromisso com a relação a dois, quando comparada com aqueles que partilhavam um espaço próprio e autônomo.

Para a realização da pesquisa de campo contei com a participação de dez pares amorosos, todos eles pertencentes aos segmentos urbanos médios da cidade de Belém, localizada no estado do Pará. Entrevistei longamente os pares e, em conjunto, durante vários encontros, falávamos de amor e de uma série de temas a ele associados.

Pela impossibilidade de um convívio mais próximo com os pares amorosos que selecionei - dada a característica do tema em estudo -, procurei, ao longo das entrevistas, investigar mais detalhadamente, por meio de indagação direta, suas percepções em torno do conceito e do significado do amor, bem como da expressão desse amor, não só em datas festivas ou ocasiões especiais, mas, acima de tudo, no cotidiano. Além das declarações expressas pelas parcerias, pude, no convívio e por minha própria conta, observar algumas destas manifestações como olhares, termos carinhosos, apelidos, deferência no tratamento, atitudes de gentileza, cuidado com o outro, da mesma forma que identifiquei conflitos, tensões, insatisfações e desejos. O conjunto destes elementos 
compõe uma espécie de desenho conjugal ou um retrato amoroso dos pares que entrevistei, e configura, por sua vez, se considerarmos a tradição antropológica, o ritual do amor.

Para efeito deste artigo, procuro dar ênfase às percepções dos entrevistados acerca do significado do amor, analisando de forma conjunta e integrada os dois universos pesquisados.

Neste sentido e de acordo com o propósito do estudo, o amor aparece revestido dos dois sentidos principais que pude identificar no decorrer de todo o processo, instigante e prazeroso, de investigação de campo. Em primeiro lugar, ele é pensado como um sentimento que envolve o par numa espécie de teia amorosa, na qual as duas pessoas envolvidas se pensam, poder-se-ia assim dizer, irremediavelmente unidas uma à outra, pelos laços que o "destino" teceu, como se estivessem desde o princípio dos tempos predestinadas a se encontrar amorosamente. Pode-se aqui identificar, tal como ocorre no campo da sexualidade (VANCE, 1995; LOYOLA, 1998, 1999; DUARTE, 2004), uma visão naturalizada (ou quase que) do amor, pois ele é tomado como algo dado, que preexiste e existe de forma independente, ainda que se torne perene na figura dos amantes. Fala-se, aqui, do que Costa (1998) chama de "crença na universalidade e na naturalidade do amor". Trata-se, neste caso, de concepções acerca do amor, de discursos elaborados sobre ele em que se mesclam concepções diversas, mas nos quais predomina a ideologia do "amor romântico" e os exemplos de amores históricos - conhecidos de todos nós - são tomados como o verdadeiro amor, pois, se Abelardo e Heloísa, Tristão e Isolda, Romeu e Julieta ${ }^{1}$ assim amaram, assim também é o amor ou devem ser todos os amores. Furtado (2008) enfatiza que neste tipo de discurso amoroso prevalece o lugar-comum:

\footnotetext{
${ }^{1}$ Aqui temos três histórias ícones sobre o amor. A do filósofo Abelardo com Heloísa, cujo romance aconteceu no século 12 e não teve final feliz, pois Abelardo é castrado pelo tio de Heloísa, que é internada num convento onde termina seus dias. A lenda de Tristão e Isolda, contada e recontada desde a idade média, narra o amor do cavaleiro Tristão, o qual, devido a um poção mágica que ingere, se apaixona por Isolda, a quem ele estava encarregado de conduzir ao rei para tornar-se sua esposa. Ambos, depois de muitas desventuras morrem: Tristão, por pensar que Isolda estava morta e esta, ao encontrá-lo morto. Por fim, a trágica e mais conhecida das três histórias: Romeu e Julieta, a tragédia romântica escrita no século XVI por William Skakespeare, que narra a história dos dois jovens cujo amor não pode se realizar devido à inimizade existente entre suas famílias, o que culmina com a morte de ambos de forma muito semelhante à narrada em Tristão e Isolda.
} 
Cada amante imagina viver a mais singular das paixões, a mais inigualável. Nenhum livro poderia lhe ensinar o que ele sente e, paradoxalmente, é como se todos os livros, todos os poemas e canções de amor falassem dele e de seu amor (FURTADO, 2008, p. 11-12).

Por outro lado - e aqui se coloca a outra visão do amor já anunciada -, quando se trata de sua vivência ou prática amorosa no cotidiano da relação, que, dentre outras formas, também se expressa no discurso sobre o amor, surge uma concepção diversa que se contrapõe (algumas vezes) àquela que acabei de enunciar ou a ela se soma: a de que o amor vai sendo construído e transformado pelo par ao longo da vida em comum; ou não, nos casos em que o par e o amor não se mantêm. Neste caso, não mais estamos diante de uma visão naturalizada do amor (ou pelo menos não tanto), pois o foco não incide agora propriamente sobre uma concepção do amor, observando-se um deslocamento de sua ênfase para a vida a dois, o que deixa entrever mudanças, conflitos e tensões que fazem parte das dinâmicas de um relacionamento amoroso. A prática amorosa desmente radicalmente a idealização, pois, como pude fartamente observar e ouvir dos pares de amantes entrevistados, todos se amam com o sentimento, mas também com razão e julgamento, o que impede (ou pode impedir) que o impulso amoroso se torne irrefreável (COSTA, 1998).

Assim, ao mesmo tempo em que existe um processo de idealização - algo a traduzir como um "imaginário" amoroso - em torno da atualização do amor ou da ideia desse sentimento, expresso, por exemplo, na fala de uma mulher heterossexual ("eu não consigo viver muito de acordo com o que eu idealizo, de acordo com o que eu penso"),há também o que referi como um elemento "novo", marcadamente presente nos meus dados de campo, expresso na ideia de que o amor motiva, ou dito mais fortemente, causa mesmo (tal qual as metades que uma a outra se procuram, à la Platão) a formação das parcerias que se unem a partir dele. Mas, ao mesmo tempo e paradoxalmente,o amor se constrói, se transforma, se consolida no exercício contínuo e cotidiano do relacionamento a dois, vivido num intenso e eficiente processo de ritualização. 
Na verdade, ainda que estas duas visões possam ser tratadas separadamente, nas falas dos entrevistados elas se sobrepõem e, devo dizer, correndo o risco de decepcionar os que me leem e que pensavam aqui encontrar um novo modelo de amor, que o nosso velho conhecido - o ideal do amor romântico - é o que se faz muito presente (em certos casos, onipresente), ainda que revestido de alguns outros “invólucros", estes sim condizentes com as mudanças que foram se dando ao longo das últimas décadas em vários campos, dentre estes o da afetividade e da conjugalidade.

Desta forma, se o amor for tomado como uma construção, como algo inventado, que sabemos que é, e, como bem dizia La Rochefoucauld desde o século XVII, "há pessoas que nunca teriam se apaixonado se não tivessem ouvido falar de amor", temos que pensar, como enfatiza hoje Costa (1998), que todos os elementos que Ihe são constituintes não são fixos por natureza, podendo, dessa maneira,ser alterados, mantidos, trocados, melhorados, piorados, o que se pode observar nos arranjos cotidianos da vida a dois que servem de fio condutor às análises que aqui teço.

No terreno da vivência amorosa, é importante considerar que ainda que eu esteja falando/tratando de um par, estou falando/tratando também de um indivíduo ou de duas entidades separadas e ao mesmo tempo juntas. É desta forma que eles pensam a si mesmos, o que me parece ser um traço distintivo que dá um toque de modernidade a esse relacionamento que, ao longo do tempo, foi assumindo uma feição muito própria, particularmente no Ocidente. É a concepção dumontiana (DUMONT, 1985) do valor do indivíduo livre e igual, largamente explorada nos trabalhos de Giddens (1992), tida por Torres (2000) como um dos temas que atravessam e aproximam a proposta da maioria dos estudiosos do amor. A ideia de uma individualização crescente implica maior margem de liberdade e escolha no plano das relações conjugais e familiares, o que torna mais complexo o estudo e a compreensão da vida cotidiana fora dos seus contextos de ocorrência.

A este respeito, Heilborn (2004) chama atenção para o conjunto de transformações que incidiram sobre a sociedade europeia a partir do século XVI, que,grosso modo, como diz ela, se definiram como modernidade e que vão dar singularidade à sociedade ocidental, na medida em que possibilitam mudanças de peso na 
vida contemporânea, como as que surgem no bojo dos estudos sobre gênero, cruciais para a mudança de percepção acerca da relação entre homens e mulheres (LOURO, 1997).

Neste sentido, mais especificamente entre os segmentos médios, o domínio dos valores relativos à família sofreu uma alteração interna, ou seja, na própria concepção de família (VAITSMAN, 1994). Não só, mas aí também se identifica a presença de uma ideologia igualitarista, expressa pela proliferação de novos arranjos conjugais (MATOS, 2000), pela desnaturalização das percepções de gênero, por uma concepção de sexualidade mais aberta que desvincula o seu exercício do âmbito conjugal (GIDDENS, 1992; BOZON, 2002 e 2004), pela ampla aceitação do divórcio e da maternidade fora do casamento (VELHO, 1986) e também pela presença de novos modelos no campo da homossexualidade (DUARTE, 2004; GROSSI, 2003; WEEKS, 2000; WESTON,1993).

Sem dúvida, ou até obviamente, estas mudanças se refletem diretamente no campo da vivência amorosa, em que a escolha, como assinala Velho (1986), passa a ser recíproca, embora não descolada de um contexto de mudanças mais amplas. Parece-me que esse tem sido o caráter dos diversos trabalhos que se aplicaram ao âmbito da conjugalidade, com ênfase na manutenção da parceria amorosa, reconfigurada ou reatualizada por conta e a partir desse quadro de mudanças que mencionei. Estou me referindo aqui ao "relacionamento puro" de Giddens (1992), ao "casal igualitário", de Heilborn (2004a), às "flexíveis e plurais", de Vaitsman (1994), ao "amor construção", de Torres (2000), aos “vínculos amorosos reinventados", de Matos (2000), aos “casais", de Bozon (2003), aos “reservados e invisíveis", de Paiva (2007), ao “casal grávido”, de Salem (2007), e, nos meus próprios termos, às “parcerias amorosas" que investiguei (AMARAL GONÇALVES, 2011).

No caso específico de meu estudo, o amor, que se apoia nas duas concepções já apresentadas -"amor romântico" e "amor construção" -, se associa a um conjunto de sentimentos e atitudes que resumi num "trio" mais expressivo: companheirismo, carinho e respeito. Não se trata apenas daquilo que Matos definiu como a "pista falsa" seguida por Giddens, dada pela ênfase no ethos do amor romântico (2000, 24), ainda que eu não possa deixar de enxergar como ele a presença desse ideal nas falas de meus 
interlocutores.O mesmo posso dizer de Torres (2000). Na verdade, este ideal está nas falas, porque está também em filmes, canções, literatura (clássica ou moderna), em ambos os formatos. Neste sentido, Gay [2000] mostra claramente que as diferentes visões do amor não foram construídas num período específico, mas gestadas desde a antiguidade e influenciaram, em maior ou menor medida, as vidas de todos nós - homens e mulheres, heterossexuais e homossexuais -, o que continua acontecendo até hoje. Ademais, este autor chama atenção para o fato de que a obra de ficção não se limita a ser apenas uma invenção, como eventualmente poderíamos supor. Sendo ela também um registro, portanto "real", num movimento fortemente dinâmico, inventa, registra e molda o que lhe dá densidade.

As associações que meus entrevistados fizeram entre companheirismo, carinho e respeito me permitem afirmar que o ideal romântico - tão citado aqui - é tido como importante e pode ser mais estritamente relacionado à ideia de carinho, que se traduz por um conjunto de atitudes como atenção, cuidado, dedicação, gentileza, querer bem e tratar bem. Por outro lado, o termo mais citado e, destarte, colocado em primeiro plano,foi companheirismo, ao qual se associam atitudes de amizade, cumplicidade, compartilhamento, convívio, copresença, parceria, sentimento de falta ou prazer pela companhia da pessoa amada. Em terceiro lugar, a ênfase coube ao termo respeito, traduzido como compreensão, consideração, paciência, tolerância e capacidade de lidar com as diferenças.

As falas a seguir dão bem o tom do que estou dizendo:

Quando a gente fala em amor hoje, o que a gente tem construído, vem a questão da amizade, companheirismo, consideração, fidelidade. Realmente, o amor ele se resume num conjunto de várias virtudes, vários sentimentos. É assim, dessa maneira, como eu sinto, como eu vejo(parceria homossexual feminina).

Eu entendo o amor assim, pra mim o amor é cumplicidade só, porque da cumplicidade vem compreensão, porque quando você é cúmplice você é compreensivo, quando você é cúmplice você é carinhoso, quando você é cúmplice você é companheiro, quando você é cúmplice você é leal, porque só há cumplicidade se houver lealdade, se houver respeito, se houver...entendeu? (parceria homossexual masculina). 
[...] eu acho que amar uma pessoa é você poder estar com ela o tempo todo tranquila, sabe? Dar direito a ela de sair, de ir e vir [...] respeito [...]. Amar é saber entender que nós somos pessoas únicas, diferentes uma da outra, nós temos os nossos pensamentos, discordamos e a gente chega a uma discussão de uma discórdia e não chegamos a um final comum; então você fica com a sua verdade e eu fico com a minha verdade e a gente respeita o ponto de vista de cada um sempre(parceria heterossexual).

Numa tentativa de síntese e pensando em torno dos tantos e densos dados de campo, uma possível leitura que faço é que o amor, ou o sentimento amoroso, não pode ser pensado/sentido/vivido dissociado desses elementos. Ainda que o carinho apareça no centro desta tríade, como se fosse o cerne, o núcleo em torno do qual tudo o mais se aglutina, o companheirismo e o respeito figuram como as extremidades, melhor dizendo, o invólucro que reveste e protege esse centro. Não se trata, portanto, de pensar apenas em termos românticos, mas de compreender que as diversas visões do amor aqui apresentadas possuem aproximações e, de certo modo, atravessam umas as outras, o que resulta na complexidade e profundidade que esta temática apresenta.

Retomando certos autores que se dedicaram ao estudo do amor, alguns dos quais considerados clássicos, pois suas visões se espraiaram por diversos campos gerando interpretações as mais diversas, algumas delas díspares, temos em Platão uma espécie de ponto de partida. A grande fonte do mito amoroso no ocidente que consolidou uma expressão que se tornou mesmo popular, o "amor platônico", representando um amor não concretizado e a busca de uma espécie de "metade" de nós que se perdeu. Deste modo, as metades se acham, elas e nós, incompletas, necessitando de um encontro e uma união para existirem plenamente. Em Platão (2007) e seu "Banquete"², temos um elemento que me parece crucial, traduzido pela ideia de que não existe um discurso único sobre o amor, e sim discursos amorosos, marcados por descontinuidades, lacunas, variações e disparidades, tal qual o amor que encontrei na vida real dos pares aqui apresentados.

\footnotetext{
${ }^{2}$ A maioria dos estudiosos concorda em ver a obra "O Banquete", de Platão, como a grande fonte do mito amoroso no ocidente, devido à enorme influência que este autor exerceu (e ainda exerce) na cultura ocidental, apesar de a obra possivelmente ter sido escrita no ano 385 a.C.
} 
$\mathrm{Na}$ chamada vida real, ainda que se busque idealmente o outro que nos falta, como encontrei em meus dados em torno da ideia de companheirismo, está sempre presente o desejo de autonomia, de liberdade, que entra em conflito com o desejo de formar um par, pela tensão que pode gerar e, neste sentido, ser vista como estruturante ou constitutiva dessa díade entre a tentativa de se preservar a individualidade e a presença de uma totalidade intrínseca à concepção de "casal”, ou parceria amorosa, denominação que utilizo mais frequentemente. Nos "casais igualitários", de Heilborn (2004), esta tensão constitui o cerne de sua discussão e de seu argumento, antes teoricamente apontado por Simmel (1993) com a ideia de autonomia, inclusive no que se refere ao prazer sexual.

Ainda que nas longas falas de meus interlocutores o termo igualdade não tenha sido mencionado de forma significativa, entendo que a ideia de respeito, também indicada como crucial, esteja em consonância com a análise de Heilborn, porque se refere particularmente à necessidade de lidar com as diferenças e parte, evidentemente, da constatação de que essas diferenças existem e não se dissolvem na ideia do par; pelo contrário, a convivência a dois deixa ainda mais visíveis as diferenças e as peculiaridades que constituem o caráter idiossincrático de cada um dos membros da díade. Assim, o desejo de manutenção da relação implica necessariamente o esforço cotidiano de compreender, ser paciente, ser tolerante, dialogar e não retardar para o dia seguinte a resolução dos problemas que surgem hoje, tal como apontaram os pares entrevistados, que ilustro com a fala a seguir, de um representante de uma parceria homossexual masculina:

Olha a gente não dorme sem...não dá pra dormir puto um com outro. Ou a gente supera isso agora, entendeu? porque estender pra amanhã é piorar a situação, porque junta isso com o estresse do trabalho, da vida, não tem condições. Tanto que um ou outro à noite, antes de dormir, vai ter que flexibilizar, repensar e dizer: olha, pois é a gente brigou por causa disso, mas vamos ver como a gente encaminha, vamos dormir bem porque não dá pra gente acordar no outro dia, aí a gente acorda e 'bom dia!', aí não rola, aí vai começar outro dia assim? Então, não dá. 
Assim, o eixo central da relação, a partir de meus dados de campo, se expressa através do desejo de ter um par, traduzido em companheirismo; da necessidade de expressão recíproca do afeto, expresso em carinho; e do respeito proclamado na ideia de igualdade e consideração das diferenças. Dito de outra forma, temos aqui a busca pelo outro à la Platão, o ideal do amor romântico, mas - e, nessa imbricação, meu achado mais precioso -, tudo isso regado pelas transformações pelas quais a sociedade tem passado e que se refletiram/refletem profundamente no campo das relações afetivas.

Giddens (1992), ao analisar as "transformações da intimidade”, chamou atenção para estas mudanças, erigindo uma espécie de modelo - o "amor confluente" -, por ele traduzido como o amor que "presume igualdade na doação e no recebimento emocionais"(p. 73). O amor confluente se contrapõe ao amor romântico, em que as categorias "para sempre e único" são tidas como centrais, pois nesse contexto menos importa a pessoa especial que o relacionamento especial, o "relacionamento puro" baseado na satisfação mútua.

Torres (2000, p.154), articulando o debate em torno deste tema com os dados coletados em campo, afirma que,"por um lado, o amor é menos um estado que suspende o tempo e o espaço e assume mais facilmente os contornos de um processo". Assim, ainda que a escolha amorosa seja uma condição necessária ao casamento (seu tema de estudo), ela não dá conta da durabilidade da relação, pois importante é que "o amor persista e a relação tenha qualidade" (idem). É assim que Torres chega ao modelo do “amor-construção", que, por minha vez, também pude identificar na fala das parcerias amorosas com as quais trabalhei. Segundo a autora, passada a fase inicial de estabelecimento da relação, o amor e a paixão se transformam num sentimento mais estável, mais “construído", como ela mesma diz. Descobrem-se aspectos novos e outros sentimentos, "desidealiza"-se o parceiro, que se torna mais previsível e possivelmente mais próximo, e também surgem tensões e conflitos que podem ocasionara desconstrução da relação. O fato é que, independentemente dessas assimetrias, o amorconstrução implicaria maior paridade entre homens e mulheres (TORRES, 2000, p.155).

De minha parte, identifiquei muito fortemente a ideia de construção nas falas dos três grupos entrevistados - parcerias heterossexuais, parcerias homoafetivas masculinas 
e parcerias homoafetivas femininas -, o que não eliminou de forma alguma o ideal romântico de "amor à primeira vista", frequentemente referido. O amor foi indicado como algo que não se encontra "pronto e acabado"; pelo contrário, à medida que o relacionamento se consolida no tempo, é fundamental que se busque sua permanência pela manutenção da relação, o que requer disponibilidade para estar junto, respeito pelos espaços individuais de cada um, apoio mútuo, permanência do interesse sexual, enfim, um conjunto de atitudes e disposições que cada um dos diferentes pares vai definindo como importante para si. Alguns depoimentos são bem representativos nesse sentido:

[...] acho que ele (o amor) vai se construindo lentamente. Pra mim você vai conhecendo a pessoa. Pra mim nem existe isso de você amar uma pessoa sem conhecer. Pra mim não existe isso (parceria homossexual feminina).

[...] eu chamo de amor, porque eu compreendo que o amor, que o conceito de amor é assim...é construção...É construção assim no dia a dia, é nas relações. Como tu vais estabelecendo o limite do teu cotidiano com teu parceiro ou com tua parceira [...] (parceria homossexual masculina).

Agora se tu quiseres minha avaliação hoje em relação a todo um processo de construção desse [...] amor, acho que hoje eu gosto mais do...eu amo mais [...] do que antes, que foi um processo [...] (parceria heterossexual).

Indubitavelmente, os relacionamentos amorosos, como procurei mostrar, apresentam uma configuração bastante característica, o que leva a pensar sempre em termos de diversidade, de dinâmica, pois os contextos de ocorrência dão um tom particular a cada uma das experiências.

Em função disso, não me atrevo em falar de um "novo" modelo ou de um amor ou discurso amoroso que sirva para todos, pois tudo o que aqui disse e que me disseram aqueles com os quais conversei sobre o amor por longas horas tem um caráter bastante específico e particular. Contudo, essas experiências particulares ganham um caráter mais geral quando articuladas com outros contextos, também específicos, ou quando situadas em debates mais teóricos sobre o tema e passam a formar o que já referi, com Platão, como os multifacetados discursos sobre o amor. 
Por fim, um último aspecto que gostaria de ressaltar, diz respeito ao exercício que fiz de pensar o amor ouvindo as histórias de amor de três grupos que muito frequentemente têm sido estudados separadamente por força das especificidades de cada um. Refiro-me às parcerias heterossexuais e aos pares homossexuais formados exclusivamente por mulheres ou por homens, cujas falas serviram de base para minhas análises.

Sempre estive ciente das especificidades que cada um destes grupos apresenta e do debate político em torno da homossexualidade. Todavia, de forma deliberada, optei por falar de amor, partindo da consideração destes três grupos. Avaliei que, agindo assim, teria não só uma visão ampliada do amor, mas compreenderia que não somente homens e mulheres amam, mas mulheres e mulheres e homens e homens também se amam entre si. Compreenderia que isto significa, ou pode significar a busca de um olhar diferenciado para as díades quaisquer que sejam, diante das teimosas hierarquias construídas para separá-las ou para Ihes impedir a expressão/manifestação/liberdade de se mostrar em contexto social.

Ademais, antropologicamente falando, ao me debruçar sobre a expressão amorosa dos grupos homossexuais que, como disse Paiva (2007), se relacionam de forma "reservada e invisível", pois se encontram fora do modelo normativo que serve de referência neste campo, foi possível enxergar as similaridades e as discrepâncias intrínsecas a cada uma destas experiências. Foi igualmente possível excluir delas a ideia de homogeneidade, muitas vezes a única admitida.

Neste sentido, esta forma de abordagem me possibilitou enxergar o quanto de exclusão e, portanto, de ausência existe em torno da temática do amor no que se refere ao universo homossexual. Nosso imaginário amoroso e nossas referências em torno deste tema se situam quase que exclusivamente (se não totalmente) no campo da heterossexualidade, ou seja, referem-se às experiências que envolvem apenas parcerias de homens e mulheres, o que remete as demais vivências amorosas ao território do exílio, para usar os termos de Costa (apud PAIVA: 2007, p. 52). São amores que nãose podem mostrar, que carecem de referências outras que não as da heterossexualidade, que se 
situam, como diz Paiva (idem), "fora das instituições que organizam as experiências de vínculo amoroso".

No entanto, ao mesmo tempo em que se situam fora, estão dentro, porque não vivem num mundo à parte; ao contrário, partilham uma experiência que lhes é peculiar, mas não exclusiva: a de amar outro, no caso, um seu igual em gênero. Por conta disso, penso que não nos é mais cabível ignorar esses outros amores que são, na verdade, os mesmos amores ou os amores de sempre, se pensados a partir da vivência cotidiana que, segundo pude inferir de meus dados, mais os aproxima que os separa.Não estou com isto querendo negar as especificidades ou a necessidade de estudo do particular, abordagem que a antropologia tanto tem privilegiado. Apenas me permiti fazer o movimento inverso e correr os riscos inerentes a tal escolha.

Finalizo, assim, estas considerações acerca do amor registrando que a vivência amorosa de meus interlocutores sofre constantemente um processo de invenção e reinvenção, tomando por base elementos já existentes, e incorporando outros que vão surgindo no bojo das transformações pelas quais passa a nossa sociedade. É isto que renova e reconfigura este campo no qual se constituem e expressam as relações amorosas contemporâneas.

\section{Referências}

AMARAL GONÇALVES, Telma. Falando de amor: discursos sobre o amor e práticas amorosas na contemporaneidade. Belém: UFPA/PPGCS, 2011.

BOZON, Michel. Sexualidade e conjugalidade. A redefinição das relações de gênero na França contemporânea. Cadernos Pagu, n.20, p. 131-156, 2003.

BOZON, Michel. Intimidade, sexualidade e individualização na época contemporânea. In: Sociologia da Sexualidade. Rio de Janeiro, Editora FGV, 2002.sim

BOZON, Michel. A nova normatividade das condutas sexuais ou a dificuldade de dar coerência às experiências íntimas. In: HEILBORN, Maria Luiza (Org.). Família e Sexualidade. Rio de Janeiro, Editora FGV, 2004. 
COSTA, Jurandir Freire.Sem fraude, nem favor:estudos sobre o amor romântico. Rio de Janeiro: Rocco, 1998.

DUARTE, Luis Fernando Dias. A sexualidade nas ciências sociais: leitura crítica das convenções. In: PISCITELLI, Adriana; GREGORI, Maria Filomena e CARRARA, Sérgio (Orgs.). Sexualidade e saberes: convenções e fronteiras. Rio de Janeiro: Editora Garamond, 2004.

DUMONT, Louis. O individualismo: uma perspectiva antropológica da ideologia moderna. Rio de Janeiro: Rocco, 1985.

FURTADO, José Luiz. Amor. São Paulo: Editora Globo, 2008.

GAY, Peter.A experiência burguesa: da rainha Vitória a Freud, a paixão terna. São Paulo: Companhia das Letras, 2000.

GIDDENS, Anthony. A Transformação da intimidade. São Paulo: UNESP, 1992.

GROSSI, Miriam. Gênero e parentesco: famílias gays e lésbicas no Brasil. Cadernos Pagu. São Paulo:Unicamp, n.21, p.261-280, 2003.

HEILBORN, Maria Luiza. Dois é par: gênero e identidade sexual em contexto igualitário. Rio de Janeiro: Garamond, 2004.

LOYOLA, Maria Andréa. A Sexualidade como objeto de estudo das ciências humanas. In: . Sexualidade: o olhar das Ciências Sociais. Rio de Janeiro: Jorge Zahar Editor, 1999.Sim, ela é a organizadora.

LOYOLA, Maria Andréa. (Org.). A sexualidade nas ciências Humanas. Rio de Janeiro: Editora UERJ, 1998.

LOURO, Guacira Lopes. Gênero, sexualidade e educação. Rio de Janeiro: Editora Vozes, 1997.

MATOS, Marlise. Reinvenções do vínculo amoroso. Cultura e identidade de gênero na modernidade tardia. Minas Gerais: UFMG, 2000.

LA ROCHEFOUCAULD. Máximas e reflexões. São Paulo: Editora Escala, 2007.

PAIVA, Antonio Cristian Saraiva. Reservados e invisíveis: o ethos íntimo das parcerias homoeróticas. São Paulo: Pontes Editores, 2007. 
PLATÃO. O Banquete. Trad. José C. de Souza.São Paulo: Abril Cultural.Coleção Os Pensadores, 2007.

SALEM, Tânia. O casal grávido:disposições e dilemas da parceria igualitária. Rio de Janeiro: FVG Editora, 2007[1987].data da $1^{\text {a }}$ edição

SHAKESPEARE, William. Romeu e Julieta. São Paulo: Martin Claret. Coleção obra-prima de cada autor, 2002[1595].data do original

SIMMEL, Georg. A filosofia do amor. São Paulo. Martins Fontes, 1993.

TORRES, Anália Cardoso. A individualização no feminino, o casamento e o amor. In: PEIXOTO, C.; SINGLY, F.; CICCHELLI, V. Família e individualização. Rio de Janeiro: FVG, 2000.

VAITSMAN, Jeni. Flexíveis e plurais. Identidade, casamento e família em circunstâncias pósmodernas. Rio de Janeiro: Rocco, 1994.

VANCE, Carole. A antropologia redescobre a sexualidade: um comentário teórico.Physis. Rio de Janeiro, v.1, n. 5. P.00-00, 1995.

VELHO, Gilberto. Subjetividade e sociedade: uma experiência de geração. Rio de Janeiro: Jorge Zahar Editor,1986.

WEEKS, Jeffrey. O corpo e a sexualidade. In: LOURO, Guacira Lopes (Org.). O corpo educado. Belo Horizonte: Autêntica, 2000.

WESTON, Kath. Lesbian/gay studies in the house of anthropology. Annual Review of Anthropology, v. 22, p. 339-367, .1993.

ZUMTHOR, Paul. Correspondência de Abelardo e Heloísa. São Paulo: Martins Fontes, 2002. 
"O nosso amor a gente inventa": discursos e práticas amorosos homo e heterossexuais

Recebido em: 19/09/2013

Aprovado em: 31/10/2013

Universidade do Estado de Santa Catarina - UDESC

Centro de Ciências Humanas e da Educação - FAED

Revista PerCursos

Volume 15 - Número 28 - Ano 2014 revistapercursos@gmail.com 